Article

\title{
Rethinking the Box for Sustainable Logistics
}

\author{
Jesús García-Arca *®D, José A. Comesaña-Benavides, A. Trinidad González-Portela Garrido \\ and J. Carlos Prado-Prado \\ Grupo de Ingeniería de Organización (GIO), Escuela de Ingeniería Industrial, University of Vigo, 36310 Vigo, \\ Spain; comesana@uvigo.es (J.A.C.-B.); tgonzalez-portela@uvigo.es (A.T.G.-P.G.); jcprado@uvigo.es (J.C.P.-P.) \\ * Correspondence: jgarca@uvigo.es; Tel.: +34-986-812220
}

Received: 22 January 2020; Accepted: 26 February 2020; Published: 2 March 2020

check for updates

\begin{abstract}
Packaging design is one of the potential strategies for increasing logistics performance, not only from a cost reduction perspective, but also from a sustainable point of view. The deployment of a sustainable vision in packaging design should demand a holistic view of packaging, supply chain and product; this integrated vision is the main point of the "Sustainable Packaging Logistics" (SPL) approach. At a logistics level, a key link with the different stages of the supply chain is the secondary packaging, which most commonly takes the form of a corrugated cardboard box. Thus, the main objective of this paper is to develop a systematic and dynamic method that makes it possible to connect design decisions about the dimensions of that box with their impact on overall efficiency and sustainability of the supply chain. In order to develop this model, the impact on three different logistics systems is described. Those systems are palletizing, multimodal containers and parcel services. Likewise, in addition to proposing the theoretical model, the authors have tested it successfully in three different companies (with the three logistics systems mentioned) following the "action research" approach.
\end{abstract}

Keywords: packaging; box; logistics; sustainability

\section{Introduction}

In increasingly competitive, turbulent and global markets, firms and, more generically, the supply chains they belong to, must promote actions that increase efficiency and sustainability, particularly within the scope of logistics and transport. Adequate goods transport management has become a strategic issue on the agendas of firms and administrations, not just because it contributes to reduced costs and improved services but also because it is a way of reducing resource consumption, $\mathrm{CO}_{2}$ emissions and traffic congestion [1-4]. In this context, packaging design is one of the key elements that can actively help improve supply chains, contributing to improved sustainability of logistics processes and activities [5-14]. Beyond the necessary and indispensable protection it provides the product, packaging should also facilitate the development of sustainability in all three of its dimensions (economic, environmental and social) [15].

The economic dimension of sustainability is related to sales promotion, i.e., improving the differentiation capacity of certain features (tangible and intangible) of the products [16,17]. At the same time, packaging design can facilitate overall cost reductions for the supply chain, including logistics costs linked to handling, storage and, particularly, transport [7,9,18,19].

In terms of the environmental dimension, packaging design also has an effect on how many or how few resources are consumed [10,20-24]. This consumption includes the materials for the packaging itself and also other resources used throughout the supply chain such as the fuel needed for transporting the goods. Likewise, packaging design has an impact on the environment by producing more or less waste or contamination. Furthermore, the environmental impact of damaged or spoilt products resulting from unsuitable packaging design should not be overlooked [25-27]. 
Finally, the social dimension of sustainability in terms of packaging design is an aspect that has not generally been developed in the scientific literature. Issues linked to packaging design's social impact include: facilitating recycling efforts, supplying honest, easy-to-understand information, safe product consumption and adaptation of the product's use, ergonomics or dose to the needs of customers such as the elderly or people with disabilities $[10,28,29]$.

Given what has been stated above about sustainability, design requirements can be understood to be multi-faceted in terms of their impact. Appropriate packaging design must meet those requirements, which are located on different levels and meet different needs (protection, commercial, logistics, environmental, etc.). However, it is not enough just to understand the multiple design requirements imposed upon packaging, even though they are important, as there is also a need to understand the structure of packaging as a system. That system is typically split into three levels [5]:

"Primary packaging". This is the first protector of the product and typically comes into contact with it; it is also called the "inner container", "first container" or "consumer package".

"Secondary packaging". This is designed to group several primary packages of the same or different products to provide them with protection and make them easier to handle during distribution and sales. This level is normally known by the generic names of "outer packaging" or "retail packaging".

"Tertiary packaging". This last level is traditionally associated with several units of secondary packaging which are grouped, for example, on a pallet or roll container to facilitate handling, storage and transport. This third level is also known as the "unit load" or "transport packaging".

The reason why both second and third-level packaging can often include one or various different products is linked to the adjustments that are made to meet the needs of the orders from a firm, store or end customer. Given that multi-product groups usually imply a break from the initial configuration established by the packing firm, using them requires additional handling that can have an effect on the efficiency and sustainability of the supply chain as a whole.

The interrelation between the first, second and third levels of the packaging system should be coherent with the different design requirements to which they are subject. Thus, given that there is considerable dependence between the three levels in order to ensure that design requirements are met, any adaptation of a level should not be assessed in isolation but rather in a joint and integrated way with the other levels.

At the same time, the variety of requirements demands a certain level of internal and external coordination in the design process. The importance placed on each design requirement depends on which area, department or firm on the supply chain is evaluating it. Moreover, the design requirements are not shared out equally over the different levels of the packaging system, and neither are they shared out equally over each stage, process and task within the supply chain [6,9,30-34].

Thus, any design decisions that should be taken would be centered around five complementary aspects that are tightly interconnected: materials selection and formats; selection of technologies related to the processes that involve the packaging (from when the product is initially packed to warehouse storage and transport, including identification methods such as RFID tags or barcodes); the packaging's aesthetic design (shape, colors, text, symbols, images, etc.); the three-level structure of the packaging system; and the selection of the dimensions on each of the levels.

Therefore, the organizational structure adopted should dynamically allow design decisions for packaging to be taken in a coordinated and consensual way among the different parties affected, i.e., different areas or departments within each firm and different firms in the supply chain (packaging manufacturers, packing companies, distributors, logistics operators, etc.) Likewise, it is desirable that this organizational structure should be coordinated and integrated with those responsible for taking decisions about product design and the supply chain. 
Addressing this issue in an integrated and all-encompassing way is the basis for the "Packaging Logistics" approach, which was first employed at the end of the 1990s in Scandinavian countries. Its academic conceptualization was developed in the works of several authors, in particular those from the University of Lund in Sweden [5,7,9,11,14,18]. Later, García-Arca et al. [11] adjusted, qualified and extended a previous definition [5] to include sustainability, coining the term "Sustainable Packaging Logistics" (SPL) which they define as: "The process of designing, implementing, and controlling the integrated packaging, product and supply chain systems in order to prepare goods for safe, secure, efficient and effective handling, transport, distribution, storage, retailing, consumption, recovery, reuse or disposal, and related information, with a view to maximising social and consumer value, sales, and profit from a sustainable perspective, and on a continuous adaptation basis".

This definition expressly mentions the processes involved, the three dimensions of sustainability (social, economic and environmental) and the dynamic view of the five design decisions associated with packaging. This dynamic view is critical in order to adapt or add detail to design requirements because of threats or opportunities in the environment. Likewise, the definition reinforces the need to integrate the three related systems: packaging, product and the supply chain itself. Finally, it strengthens the idea of linking packaging design with competitive improvement of the firm, i.e., gaining better business results.

In this context, it would seem reasonable to define the "best" packaging as that which simultaneously combines the most attractive and useful design for the customer, the lowest overall cost and the smallest environmental impact (including reduced losses and spoilt product). That said, most firms see cost reduction as a sufficiently attractive reason for promoting changes in their packaging. However, when the "goodness" of a particular packaging alternative is measured from other perspectives besides cost, the comparison system is not so clear and, in many cases, it is not easy to express any change in purely economic terms.

This is the case of measuring environmental impact in the classical way, which usually employs a scale that is not economic, typically the LCA technique (Life Cycle Assessment) [35], which enables measurement of the carbon footprint generated not only by the packaging but also, more globally, by the products throughout their life cycle. However, the technical expertise required when applying this technique has put many supply chain agents off doing so and promoted the emergence of adapted systems that are less complex to apply [36]. In all events, recent works have highlighted the scarcity of systems for measurement and comparison that objectively allow and facilitate the link between packaging design decisions and the supply chain's overall impact. That situation has motivated the development of this paper.

At the same time, most of the recent papers related to packaging design mainly focus on case studies $[11,14,16,18,37-40]$ or packaging product comparisons [22,23,28,41-46]. However, most of these references sidestep quantitative aspects associated with design decisions, which tends to hinder any generalization or replication of results in other contexts or settings other than the one specific to the case study or product.

In terms of logistics, it is the secondary packaging that without doubt has links with the different stages of the supply chain. When it comes to grouping products and/or primary packaging, the secondary packaging can adopt many forms (plastic pack, drum, etc.), although the cardboard box is the most widely-used basic format. The cardboard box, which is flexible and easy to make and recycle, has become, on its own merits, a mainstay of modern logistics. In this context, the main aim of this paper is to develop a systematic method for connecting secondary packaging design decisions (cardboard box) with the measurement of overall efficiency and sustainability of the supply chain. However, although all decisions taken in packaging design are relevant, the proposed method is centered particularly within the scope of decisions regarding box dimensions.

The search for methods to identify the best box has been approached in various ways in recent studies, although none have the comprehensive approach that is proposed here. Some authors have developed techniques and tools that seek to optimize box size or load units with quantitative approaches 
(heuristic techniques, metaheuristics and integer programming), although they have been taken out of the global logistics context and sidestepped any environmental impact [47-50]. Other publications have concentrated on partial views of the chain such as the production stage. Meanwhile, others have integrated the logistics and environmental viewpoints, but they have done so by focusing on a single box type or logistics system (palletized systems in particular; [51]). Other sources have looked in depth at the benefits of standardization of packaging dimensions $[13,52,53]$, including the impact on productive efficiency of "packaging postponement".

At the same time, beyond proposing only a theoretical method, the authors have tested it in three different companies following the "action research" approach. This approach implies that the authors participate directly in the work teams, leading and coordinating the implementation of the method. Thanks to this involvement, the researchers have the opportunity to witness the process not only as mere observers but also as real "agents of change" in intervention and knowhow-compiling processes [54,55]. According to some authors [56-59], there are scarce references to adoption of the "action research" approach in the field of supply chain management and, particularly, in relation to packaging design.

\section{Method Proposal}

As mentioned, the proposed method attempts to connect box design decisions-particularly those concerning dimensions-with measurement of the overall efficiency and sustainability of the supply chain. It is structured in 5 stages:

1. Formation of the working team. This multidisciplinary team will be responsible for the five packaging design decisions. It includes representation of the different viewpoints and perspectives related to those decisions both within the packaging company and outside it (packaging manufacturers, distributors, logistics operators, etc.). Following the "Action Research" approach, the authors actively participate in this team, coordinating and supervising its work.

In this setting, direct involvement of the authors in work team meetings enriches the process of reflecting on the model conceptually. This systematic method of knowledge and experience exchange between the authors and the firm has been the "triangulation" proposed by some references $[58,60]$ and was not only necessary to bestow scientific rigor on the model under an "Action Research" approach but also to lay down the foundations for desired future replication on a wider empirical basis $[4,59]$.

2. Preliminary analysis of the logistics system. During this stage there is an analysis of the logistics aspects on the supply chain which involves packaging. Thus, the design requirements (and their relative importance) are identified in relation to the primary, secondary and tertiary packaging. Associated costs are also included.

The basic metric for comparison of the different design alternatives will be those costs. Therefore, both direct costs and indirect costs are included in the analysis. Direct costs are those that appear directly on the firm's cost accounting sheets and are typically linked to buying the packaging; indirect costs are linked to logistics (handling, storage and, particularly, transport).

Logically, the model should include a quantitative system to evaluate environmental aspects. This is done by opting to continue with a cost-based system and using the packaging waste management costs (Green Dot). Choosing this system facilitates the analysis, although one drawback is that some environmental aspects may not be fully reflected. However, it is also true that, indirectly, reduced consumption of resources (packaging materials or transport fuel) are also associated with a reduction in the costs of buying the packaging and the overall logistics costs. Therefore, if fewer resources are consumed (or made better use of), then less waste or contamination is produced, which means that the environmental impact is also reduced in line with the reduction in costs.

3. Definition of the framework based on the volume and type of box. This stage is the core of the model because the information gathered in the previous stage is used to establish the conceptual basis that conditions the product and its associated primary packaging (if there is one), and links it to the scope of logistics, which will affect the design of the box and tertiary packaging (if there is 
one). This stage also contains design decisions related to the materials (and their associated properties, including the quality of the cardboard), the number (or range) of primary packages or products per box, the packaging technology, and the aesthetic or commercial aspects that could condition selection of a design.

A key outcome of this analysis is the volume (or range of volumes) that the working team will need in order to define the alternative dimensions of the box. Logically, their decisions about the volume and type of box will cause feedback, that is, they will affect and be affected by any earlier decisions (for example, the size of the product, the size of the primary packaging or the number of primary packaging units per box). In order to understand how this stage works in a quantitative way, some aspects linked to the type of box, the decisions about the dimensions and repercussions within the scope of logistics will be developed later.

4. Dimensional analysis of the alternatives. On the basis of the options identified in the previous stage, the working team analyses the impact of each option on the efficiency and sustainability of the supply chain, using the costs structure defined in stage 2 as a reference. This is the stage prior to selection of the most suitable design alternative.

Logically, this impact is conditioned by the type of logistics system the firm has selected. Three different-and widely-used-logistics systems have been chosen in this model: a pallet-based logistics system, an intermodal container-based system, and a parcel service-based logistics system (of the type used for online commerce). The links between box design and these systems will be commented on later.

5. Validation, fine-tuning and implementation. Once the impact of the different alternatives has been measured, real-world trials are carried out with the selected alternative in order to validate its forecast performance in the logistics system. Logically, some fine-tuning or changes in the solutions will result from these trials, which will mean stages 3 or 4 need to be re-run. Once a solution's feasibility has been validated, it is implemented.

6. Periodical review. In line with the dynamic, continuous improvement-based perspective of the "Sustainable Packaging Logistics" approach, the firm should periodically review the need to trigger the method again due to substantial changes in the design requirements such as those stemming from, for example, product demand, marketing, technological opportunities or threats (new materials, equipment, etc.), regulations, costs or modification in the logistics system.

\subsection{Dimensional Considerations and Selection Techniques for the Cardboard Box}

Corrugated cardboard is the result of joining various sheets of paper (with specific qualities) that are kept the same distance apart because one or more pieces of corrugated paper are placed between them. This configuration gives corrugated cardboard properties of rigidity, resistance and protection. Logically, there are several variations on this basic idea using different numbers of layers or employing different materials. The weight of the paper, its quality (new or recycled) and the height of the corrugations will determine the card's consistency (measured using the ECT; Edge Crush Test) and, particularly, its resistance to vertical compression (BCT; Box Compression Test). This latter parameter is one of the most important ones in logistics terms as it indicates the weight the box can withstand when in a static pile and when moving (bearing in mind the accelerations it can suffer during handling and transport as it passes along the supply chain). The key production process in corrugated cardboard manufacture is the "corrugator" machine. The packaging material is divided into two main areas: making the sheets of card in the corrugators-the combination of different types of paper-and converting them, which includes cutting and printing as well as the conversion of the sheets into flat bases that can be sold as boxes.

FEFCO (European Federation of Corrugated Board Manufacturers; www.fefco.org) is a non-profit organization based in Brussels which has represented the interests of the corrugated board industry since it was founded in 1952. The Federation's wide range of activities runs from technical to economic aspects. Those activities include standardization of the qualities and formats for cardboard boxes and 
according to the FEFCO catalogue, there are over 50 different box formats, although from a quantitative point of view, this paper is only going to deal with the three most common (see Figure 1): the slotted box, the lid and base box (telescope) and the folder-type box.
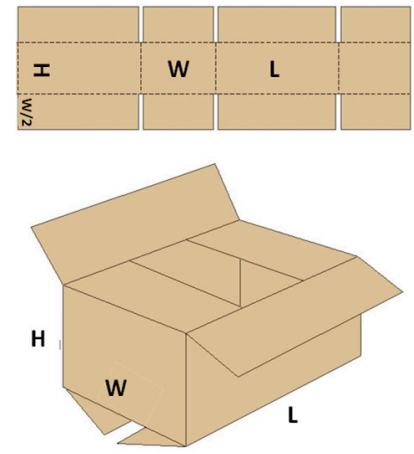
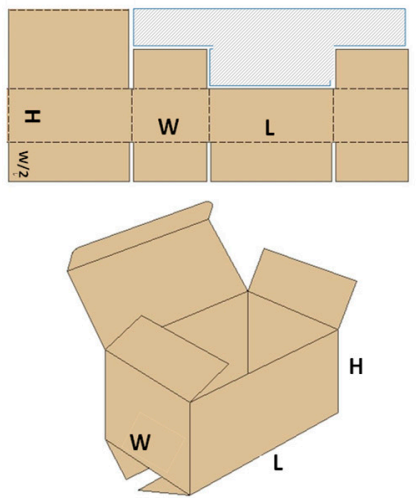
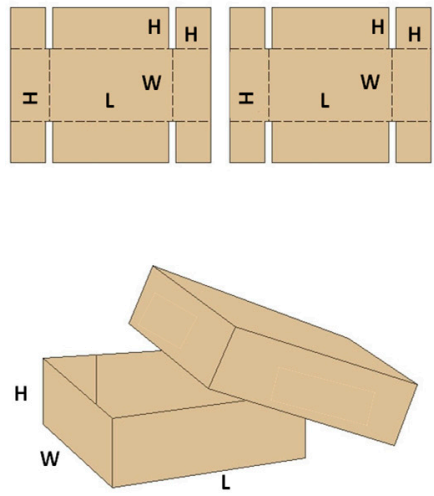

Figure 1. Three common box configurations: slotted, folder and telescope boxes (from left to right).

Selecting the box format, with its associated dimensions and technical features, is not a simple decision because the amount of material used (and waste generated) in its manufacture will depend on those characteristics. Logically, the choice of box type will also condition the technical performance and strength.

So, by defining the box type and the range of external volume $(\mathrm{V})$ available for containing the primary packaging or products, it is feasible to establish the box's theoretical surface area (S) that can be used in the manufacture of the box (and its waste) as a function of its external dimensions (length, L; width, $\mathrm{W}$; height, $\mathrm{H}$ ), which together create the volume mentioned.

Clearly, the surface area of cardboard used in the box must include any parts of the board sheet that are not used (wasted) once it is out of the corrugators- the shaded area in the figure showing the example folder-type box. This waste can be significantly reduced when the box area is replicated efficiently on the sheet of board. Likewise, the waste from the sheet is also conditioned by the dimensions themselves. In the model, in order to ease calculation, the surface area for the sticking flaps (in the slotted box and folder-type) and the margin for making the base box and lid fit have been eliminated so both elements were considered to be equal in the calculations.

In this context and with these considerations, for each volume and box type, a length-width-height relationship can be established that minimizes cardboard consumption (the box's surface area) by means of the partial derivatives according to volume V (see Table 1). This calculation can be used to create a graph that relates this optimum necessary area of cardboard and the external volume for each type of box. Below the optimum line is the "Not Possible" area, where it is not feasible to find valid solutions. Therefore, all the feasible alternatives are above the line marking the optimum alternatives for each type of box (see Figure 2). 
Table 1. Types of boxes and calculation of optimal box surface.

\begin{tabular}{cccc}
\hline & Slotted Box & Folder Box & Telescope Box \\
\hline \multirow{3}{*}{ Box Surface } & & $\mathrm{S} 1 \rightarrow 2^{*}\left(\mathrm{~W}^{*} \mathrm{H}+\mathrm{L}^{*} \mathrm{H}+\mathrm{W}^{2}+\right.$ & $\left.\mathrm{W}^{*} \mathrm{~L}\right)$ \\
& $2^{*}\left(\mathrm{~W}^{*} \mathrm{H}+\mathrm{L}^{*} \mathrm{H}+\mathrm{W}^{2}+\mathrm{W}^{*} \mathrm{~L}\right)$ & $\begin{array}{c}2^{*} \mathrm{H}^{*} \mathrm{~L}+2^{*} \mathrm{~W}^{*} \mathrm{H}+3^{*} \mathrm{~W}^{2}+ \\
3^{*} \mathrm{~W}^{*} \mathrm{~L}\end{array}$ & $\begin{array}{c}2^{*}\left(4^{*} \mathrm{H}^{2}+2^{*} \mathrm{~W}^{*} \mathrm{H}+\mathrm{W}^{*} \mathrm{~L}+\right. \\
\left.2^{*} \mathrm{~L}^{*} \mathrm{H}\right)\end{array}$ \\
& & $\mathrm{L}(1)=\left(2^{*} \mathrm{~V}\right)^{1 / 3}$ \\
Optimal dimensions & $\mathrm{W}(1)=(\mathrm{V} / 4)^{1 / 3}$ & \\
& $\mathrm{~L}=\left(2^{*} \mathrm{~V}\right)^{1 / 3}$ & $\mathrm{H}(1)=\left(2^{*} \mathrm{~V}\right)^{1 / 3}$ & $\mathrm{~L}=\left(4^{*} \mathrm{~V}\right)^{1 / 3}$ \\
& $\mathrm{~W}=(\mathrm{V} / 4)^{1 / 3}$ & $\mathrm{~L}(2)=2^{*}(\mathrm{~V} / 6)^{1 / 3}$ & $\mathrm{~W}=\left(4^{*} \mathrm{~V}\right)^{1 / 3}$ \\
& $\mathrm{H}=\left(2^{*} \mathrm{~V}\right)^{1 / 3}$ & $\mathrm{~W}(2)=(\mathrm{V} / 6)^{1 / 3}$ & $\mathrm{H}=(\mathrm{V} / 16)^{1 / 3}$ \\
& & $\mathrm{H}(2)=3^{*}(\mathrm{~V} / 6)^{1 / 3}$ & \\
\hline \multirow{2}{*}{ Optimal box surface } & $18^{*}(\mathrm{~V} / 4)^{2 / 3}$ & $\mathrm{~S} 1 \rightarrow 18^{*}(\mathrm{~V} / 4)^{2 / 3}(\mathrm{~V} / 2)^{2 / 3}$ \\
\hline
\end{tabular}

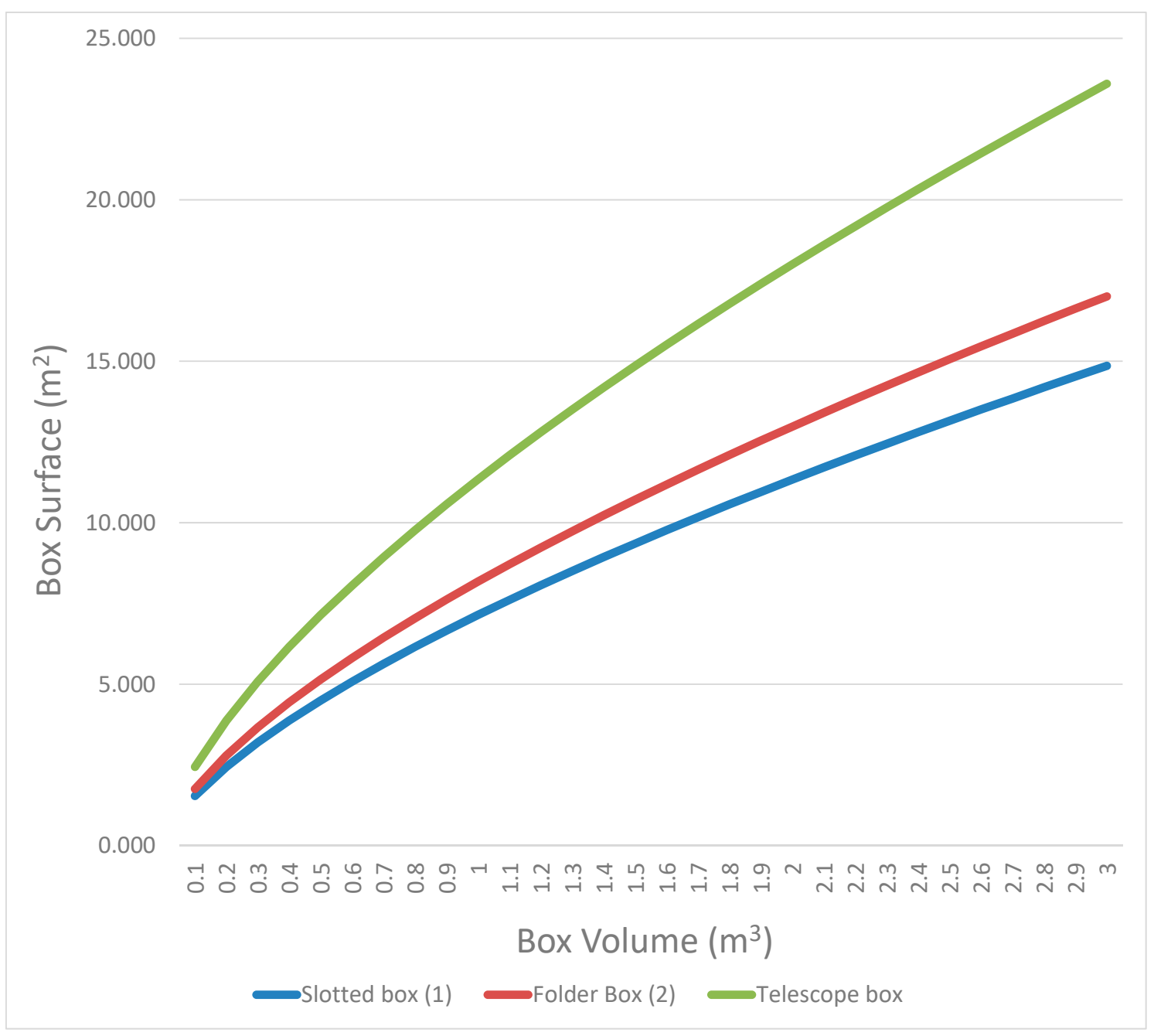

Figure 2. Calculation of surface development in boxes according to volume.

To make things clearer, it should be pointed out that for the folder-type box, there is not so much a line but an area (between lines 1 and 2) in which the optimum solution would be located. This approximation is necessary because of the dependence the box surface layout has on the sheet of cardboard. Thus, line 1 coincides with the slotted box, without considering any waste in manufacturing (S1). Line 2 includes the maximum waste in the sheet of cardboard (shaded area) when manufacturing (S2). Figure 2 shows the slotted box's most efficient behavior compared to the other two types. Logically, other considerations can be of greater relevance in the selection (for example, commercial or 
strength considerations), which would make the other box types more interesting even though they are more inefficient.

The larger the boxes are in terms of useful volume (for one type), the smaller the relative consumption of cardboard (and waste) per $\mathrm{m}^{3}$ (Figure 3). This is a critical aspect of the proposed model, given that its ultimate aim is to seek solutions that improve the $\mathrm{m}^{2} / \mathrm{m}^{3}$ ratio among the feasible solutions on the graph (ideally, the optimum one). This makes it possible to move towards consuming relatively less cardboard (and creating less associated waste). Nevertheless, using bigger packaging can have negative impacts in terms of ease of packing, handling, stock levels or adaptation to consumer needs.

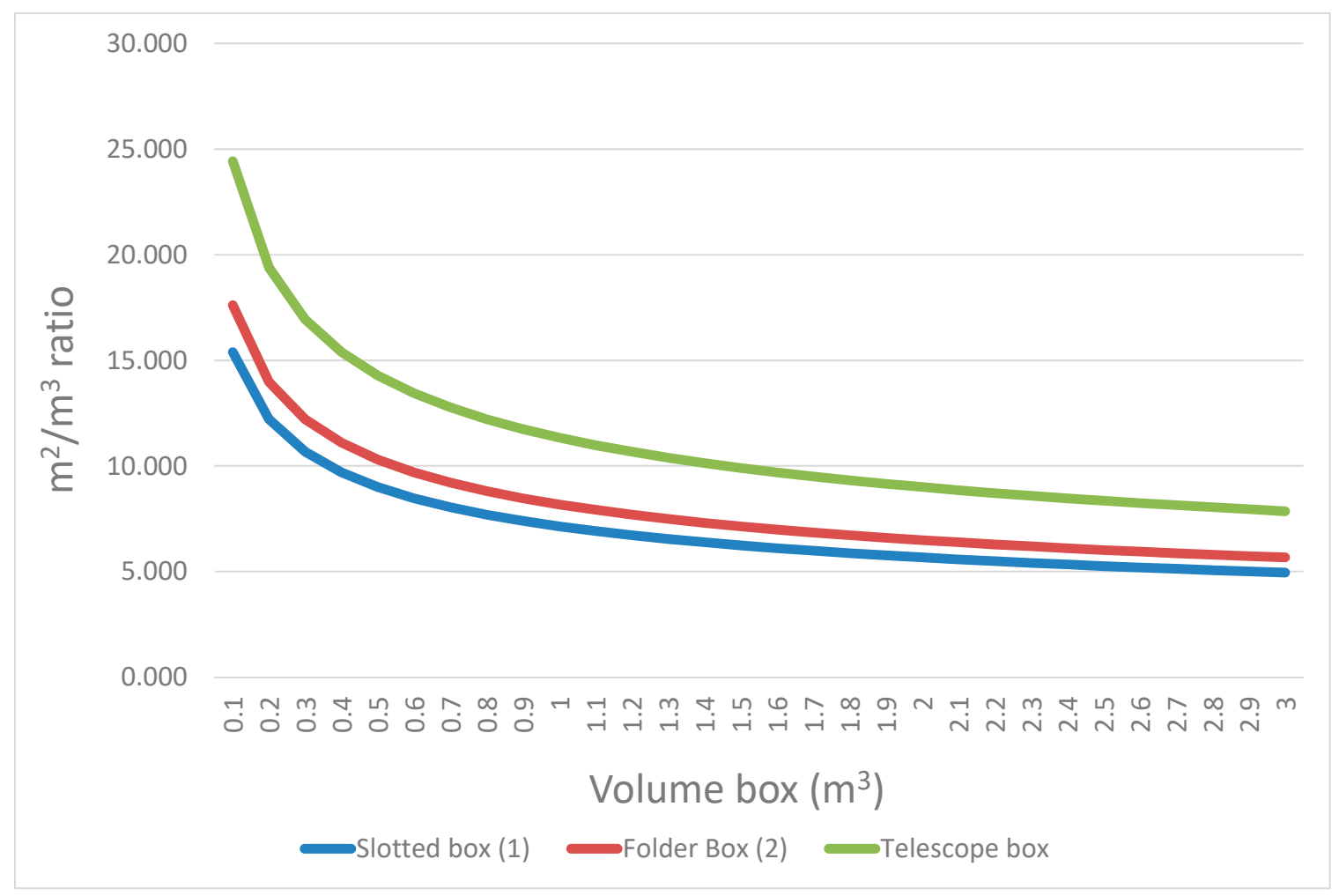

Figure 3. Calculation of $\mathrm{m}^{2} / \mathrm{m}^{3}$ ratio in boxes according to volume.

At the same time, changing the box is also a way of pursuing logistical efficiency; therefore, preference is given to exploring feasible alternatives on the graph that are also efficient in logistics terms. However, as mentioned previously, this view of box rationalization in terms of cost and environmental impact must also consider the box's role in facilitating, simplifying and cheapening logistics flows, particularly transport. Therefore, the restrictions on the resources used by these logistics flows must be understood. Below, they are described as three different systems: palletizing, containers and parcel services.

\subsection{Logistics Considerations: Palletizing and Box Selection}

One great invention that has promoted logistics efficiency worldwide was the development and spread of pallet-based systems, particularly in the second half of the 20th century. Work has gone on to standardize box dimensions in order to foster efficient pallet use. That is why the use of the $600 * 400 \mathrm{~mm}$ module (and submultiples: $300 * 400,200 * 400,150 * 400,120 * 400 ; 600 * 200,300 * 200$, $200 * 200,600^{*} 133,200^{*} 133,150^{*} 133,120^{*} 133,600^{*} 100,300^{*} 100,200^{*} 100,150^{*} 100$ and $120^{*} 100$ ) for the external dimensions of the box base has been promoted in accordance with ISO 3394:2012 standard [61]. Using the $600 * 400$ module facilitates efficient use of the base of the most widely-used ISO pallets, i.e., the EUR pallet measuring $1200^{*} 800 \mathrm{~mm}$ and American pallet measuring $1200^{*} 1000 \mathrm{~mm}$ [62]. 
Box dimension standardization also largely facilitates the dimension standardization of resources for handling, storage and transport-in turn facilitating the automation of some logistics processes.

Clearly, in addition to the dimensional combinations in packaging stemming from the $600^{*} 400$ modular proposal, there are specific non-modular efficient solutions for a pallet format, i.e., the EUR pallet or the American pallet. For example, a packaging base of dimensions $266^{*} 400$ is not included among the alternatives for the $600^{*} 400$ module but it can be palletized efficiently on the EUR pallet, although not on the American one.

In this context, the definition of height standards for these loading units seems not only recommendable but almost obligatory. a defined height standard for a palletized load would make it possible, after accounting for the height of the pallet itself-around $14 \mathrm{~cm}$ on a standard pallet-to calculate packaging heights on the basis of the number of layers. This is a key element for determining-using the modular base (or its associated multiples) — the useful work volume (V) that will allow primary packaging or products to be contained in a way that also uses efficient palletized load units. In many cases, if the protection of the product allows it, the box on the pallet can be rotated to achieve better use of the volume.

The recommended height for palletized loads should be related to the internal useful height of the transport vehicles. As a general rule, the maximum height (including pallet) of palletized loads (single product) should be $2.6 \mathrm{~m}$ (if pallets are piled up, then the maximum height would be $1.3 \mathrm{~m}$ ). Clearly, this standard is only applied provided that the specifications of the product (including rotation), its protection and its stability allow it throughout the supply chain $[63,64]$. For products needing a controlled temperature, the maximum height per palletized load is $2.4 \mathrm{~m}$ in order to allow air to circulate within the vehicle. The justification for the reference maximum height is based on optimized use of trailer lorries and the dimensions of their cargo area. In real terms, because of load stability considerations, the usual maximum height for the load is between 2.1 and $2.2 \mathrm{~m}$.

\subsection{Logistics Considerations: The Multimodal Container and Box Selection}

Another great invention that has promoted logistics efficiency was the development and spread of the multimodal container. Just as in the deployment of palletizing, a key element in the spread and consolidation of container traffic has been format standardization. Currently, the most widely-used and recognized ISO standards are the 20-foot and 40-foot containers [65].

In addition to the common standard, there are other dimensions with an alternative volumetric capacity such as the 45-foot long container or the "High Cube", which takes the 40-foot base but has greater height at 9.6 feet. Unfortunately, standardization of these dimensions has been done with no reference to the standardization of pallets. In fact, one of the unexplainable aspects of logistics standardization has been the poor or non-existent coordination between pallet standards (based on a modular concept) and container standards. This has meant that it is not possible to fill any of the containers mentioned above efficiently with any of the usual American or EUR pallets as there is always wasted cargo space. It is quite common, therefore, for containers not to carry palletized goods but stowed goods instead (typically in boxes).

This last consideration means that it is necessary to play with the dimensional range of the boxes (and their associated volume) in order to determine the alternatives that make best use of the container (greatest level of filling). In many cases, if product protection allows it, some or all of the boxes can be rotated in the container to achieve better use of the available volume. However, in addition to all the common containers in the world, there is another type called the ISO "pallet wide", which has an interior designed to make all the area palletizable in an optimum way. Unfortunately, these containers are not available at all ports or on all routes and, moreover, they are more expensive to charter.

\subsection{Logistics Considerations: Parcel Services and Box Selection}

"E-commerce" has revolutionized worldwide distribution and yet lives alongside and competes with other channels for commerce based on physical stores. In this context, the sudden emergence and 
development of this new channel has been associated with new challenges and logistics models which involve the redesigning of a good number of the processes, particularly those to do with handling, warehousing, transport and returns. In the main, transport for "e-commerce" logistics is based on parcel service companies, which face very different problems from those in the worlds of pallets and containers described earlier. The new logistics challenges caused by the development of e-commerce also have major repercussions on box design. Among these repercussions are those cited in [66-70]:

An additional box is usually needed, which some authors call "express packaging". The job of this secondary packaging is to group and protect the primary packages from the different products included in the customer's order.

Therefore, from a protection point of view, the product loses the "accompaniment" of grouping for the final leg of the supply chain, which means that additional protection material must be used (filling or cushioning) and, logically, this adds to the volume (and weight) of the new boxes.

The picking process in warehouses has become more complex given that different types of primary packaging have to be grouped within the new box in such a way that volume and weight are kept at a minimum. Logically, the need to group different product types also exists when using pallets (multireference pallet) or containers (a grouping container with different types of products and boxes), although the diversity of groupings for parcel services is much greater and has to be done much more quickly.

Given that the greatest logistics challenge for e-commerce is the so-called "last-mile problem", when the goods are delivered directly to the end customer, the design of the box-its volume, weight, ergonomics, protection and safety-also plays a significant role in how transport is best used. On the other hand, the need for differentiation and communication at the point of sale and other properties (for example, anti-shoplifting systems) disappear and, consequently, this can affect the design of the primary packaging, reducing its volume and simplifying it. This all affects the box used to group things too.

From an environmental point of view, the fact that larger numbers of boxes are being handled, and that they are bigger and have a significantly greater percentage of weight and volume devoted to protection and cushioning, means that the resources they consume (raw materials, transport, etc.) and the waste they create are also increasing.

Likewise, although reverse logistics for item returns was traditionally centered on points of sale (which made it easier), the reverse logistics for e-commerce starts, in many cases, at the customer's home. This requires a suitable box (typically and desirably the original one) in order to protect the product as it returns.

In this electronic context, it would be interesting to have a wide range of boxes with different volumes available when picking, which would allow for dynamic, agile, efficient and sustainable adaptation in order to meet the needs of the different orders (in terms of materials, waste and transport). However, this paper has so far focused on the advantages of adjusting the box in order to be efficient and sustainable by altering its size and type. Such an approach is usually sufficient in a setting where the structure of the primary, secondary and tertiary packaging undergoes very few modifications. However, what happens when that structure has to change "radically" with each order in terms of its secondary packaging? Furthermore, having a broad assortment of box formats available could be inefficient in terms of economies of scale when buying them (purchase batch sizes).

So, standardizing the number of box formats can have a positive effect on purchases, but it could be counterproductive when transport or the environment are considered because it does not use the box's volume available for grouping, which has to be filled with cushioning. On the other hand, 
format standardization also has beneficial effects when automating some logistics processes such as handling or picking.

An adequate analysis of overall costs should, therefore, determine whether it is better to use a wide range of box formats (despite each one needing a small batch order when bought) that optimizes volume, or to use fewer formats (more standard ones and with better batch orders when bought) which perform worse in terms of logistics and the environment.

The transport tariffs in parcel service logistics companies are usually applied in bands for weight ranges, distances to the destination and number of boxes. However, in order to apply the transport tariffs properly, the volumetric weight of the box must be known as well as its actual weight. The concept of volumetric weight attempts to adjust for the effect of deliveries for which the volume of the box is proportionally greater than the actual weight, that is, it refers to that "extra space" that the goods take up in the truck or plane.

To calculate the volumetric weight, the formula is applied:

$$
[\text { Length } \times \text { Width } \times \text { Height }] / N \text {, }
$$

where $\mathrm{N}$ is a coefficient that varies depending on the transport company. The lightest deliveries take up the most space in the plane or other vehicle in regard to its weight. The volumetric weight is calculated and compared with the actual weight of each box in order to determine which is greater, so that the greater of the two tariffs for these two weights can be applied. This means that for each box weight, there is an ideal volume, above which additional logistics costs can be applied. Given that transport tariffs are not applied lineally but by using weight bands, it is important to adjust the ideal volume, particularly when it involves a change of band for the tariff.

\section{Case Studies}

This section describes the application of the proposed model in three firms with very different supply chains: the pallet system, the container system and parcel services. Each project ran over a four-month period with meetings of the work teams every week or fortnight. The authors and specific heads of internal departments linked to design decisions systematically participated at the meetings. Likewise, depending on the stage the project was at, there was also participation from external firms such as the packaging suppliers and transport providers. Involvement from these firms was critical, particularly in stage 5 , when testing and final validation of the proposed packaging took place. The results, conclusions and agreements reached at all the meetings were recorded in the minutes. Those minutes were not only used as a means to reach the objectives of the project at each firm, but also as the basis for reflection and discussion on the model at a conceptual level.

\subsection{Case 1. Paletized System}

Case 1 is a Spanish firm, founded in the late 1990s, specialized in the processing and sale of frozen seafood products. Its factories handle some 30,000 tonnes annually. In 2019, the firm employed more than 300 people, and its revenue reached 75 million euros. In a bid to improve its competitive position in the market, the firm launched a logistics costs rationalization process, in which packaging redesign was of particular importance. Products packaged in the firm's factories are mainly distributed in the European market by means of EUR pallets with a maximum height of $2.1 \mathrm{~m}$ (including the pallet base).

A working team was set up to focus on improving the efficiency and sustainability of the boxes for the firm's bagged products. The participants of this team were the head of the logistics/production area, the head of purchasing, the head of sales and the authors of this paper.

Theoretically, more alternatives for settling or placement can be found for the bags inside the box (or boxes) than for rigid packaging. The different bagged products were packed in 3 different slotted boxes, labelled independently for commercial reasons, which meant that using format and dimension standardization was not considered. As mentioned, the systematic analysis of the proposed 
method included identifying the box's initial volume $(\mathrm{V})$, and playing with various factors-different combinations of box dimensions, product placement, primary packaging, and number of bags per box (when commercially feasible). This was done in an attempt to make best use of the maximum height of the palletized unit $(2.1 \mathrm{~m})$.

The first box ("box 1") did not have a modular base, although it was efficient for the EUR pallet and the maximum load height. Thus, without changing the number of bags per box, because of commercial restrictions, a volume reduction per box of $5.1 \%$ was achieved, using $17.2 \%$ less cardboard and increasing the number of bags per pallet by $6.7 \%$ (from 4050 to 4320 ). This improvement meant a reduction in the $\mathrm{m}^{2} / \mathrm{m}^{3}$ ratio of $10.6 \%$ (see Table 2).

Table 2. Summary of changes in boxes.

\begin{tabular}{|c|c|c|c|c|c|c|c|}
\hline $\begin{array}{c}\text { Type of Box } \\
\text { (External Dimensions; } \\
\text { L }^{*} \mathbf{W}^{*} \mathrm{H}, \mathrm{mm} \text { ) }\end{array}$ & $\begin{array}{l}\text { Bags Per } \\
\text { Box }\end{array}$ & $\begin{array}{c}\text { Boxes Per } \\
\text { Pallet }\end{array}$ & $\begin{array}{l}\text { Bags Per } \\
\text { Pallet }\end{array}$ & $\begin{array}{c}\text { External } \\
\text { Volume in Box } \\
\qquad\left(\mathrm{m}^{3}\right)\end{array}$ & $\begin{array}{c}\text { Box Surface } \\
\left(\mathrm{m}^{2}\right)\end{array}$ & $\begin{array}{c}\mathrm{m}^{2} / \mathrm{m}^{3} \\
\text { ratio }\end{array}$ & $\mathrm{m}^{2} / \mathrm{bag}$ \\
\hline Initial Box $1\left(400^{*} 266^{*} 130\right)$ & 30 & 135 & 4050 & 0.0138 & 0.527 & 38.13 & 0.01758 \\
\hline $\begin{array}{c}\text { Improved Box } 1 \\
(400 * 200 * 164)\end{array}$ & 30 & $\begin{array}{c}144 \\
(+6.66 \%) \\
\end{array}$ & $\begin{array}{c}4320 \\
(+6.7 \%) \\
\end{array}$ & $\begin{array}{c}0.0131 \\
(-5.1 \%) \\
\end{array}$ & $\begin{array}{c}0.437 \\
(-17.2 \%) \\
\end{array}$ & $\begin{array}{c}33.29 \\
(-12.7 \%) \\
\end{array}$ & $\begin{array}{c}0.01456 \\
(-17.2 \%) \\
\end{array}$ \\
\hline Initial Box $2(600 * 200 * 244)$ & 15 & 64 & 960 & 0.0293 & 0.710 & 24.26 & 0.04736 \\
\hline $\begin{array}{l}\text { Improved Box } 2 \\
(600 * 200 * 279)\end{array}$ & $18(+20 \%)$ & $\begin{array}{c}56 \\
(-12.5 \%)\end{array}$ & $1008(+5 \%)$ & $0.0335(+14.3 \%)$ & $0.766(+7.9 \%)$ & $\begin{array}{c}22.89 \\
(-5.7 \%)\end{array}$ & $\begin{array}{c}0.04258 \\
(-10.1 \%)\end{array}$ \\
\hline Initial Box $3\left(375^{*} 300^{*} 139\right)$ & 8 & 112 & 896 & 0.0156 & 0.593 & 37.9 & 0.07408 \\
\hline $\begin{array}{c}\text { Improved Box } 3 \\
(300 * 200 * 279)\end{array}$ & 8 & 112 & 896 & $0.0167(+7.1 \%)$ & $\begin{array}{c}0.479 \\
(-19.2 \%)\end{array}$ & $\begin{array}{c}28.61 \\
(-24.5 \%)\end{array}$ & $\begin{array}{c}0.05987 \\
(-19.2 \%)\end{array}$ \\
\hline $\begin{array}{c}\text { Improved Box } 3 \\
(400 * 200 * 279)\end{array}$ & $13(62.5 \%)$ & $\begin{array}{c}84 \\
(-25 \%)\end{array}$ & $\begin{array}{c}1092 \\
(+21.9 \%)\end{array}$ & $0.0223(+42.7 \%)$ & $\begin{array}{l}0.575 \\
(-3 \%)\end{array}$ & $\begin{array}{c}25.75 \\
(-32 \%)\end{array}$ & $\begin{array}{c}0.04421 \\
(-40.3 \%)\end{array}$ \\
\hline
\end{tabular}

The second box ("box 2") was modular in its dimensions and made full use of the EUR pallet's base and height limit. The option here was to study the possibility of increasing the number of bags per box. Logically, this was done with the approval of the customers. The aim was to look for improvements in the $\mathrm{m}^{2} / \mathrm{m}^{3}$ ratio and in how the pallet was filled. That approach led to a volume increase per box of $14.3 \%$, which in turn led to an increase in the number of bags per box of $20 \%$ (from 15 to 18 ) and of bags per pallet of $5 \%$ (from 960 to 1008). To achieve this it was only necessary to increase the amount of card used in the new box by $7.9 \%$, which was an improvement in the $\mathrm{m}^{2} / \mathrm{m}^{3}$ ratio of $5.7 \%$ and the $\mathrm{m}^{2} /$ bag ratio of $10.1 \%$ (see Table 2 ).

Finally, the third box ("box 3") did not have a modular base initially. Two alternatives were explored in this case: maintaining the number of bags per box and increasing that number. Thus, by maintaining the number of bags per box, change was centered exclusively on reducing the amount of cardboard consumed by $19.2 \%$. On the other hand, by increasing the number of bags per box by $62.5 \%$ (from 8 to 13 bags), the amount of cardboard in the box was reduced by $3 \%$ and its useful volume was increased by $42.7 \%$. At the same time, there was an increase in the number of bags per pallet of $21.9 \%$ (from 896 to 1,092 ), with a $\mathrm{m}^{2} / \mathrm{m}^{3}$ ratio reduction of $32 \%$ and a $\mathrm{m}^{2} /$ bag ratio reduction of $40.3 \%$ (see Table 2 ). This second alternative, which was more radical from a commercial standpoint, was the one chosen in the end. Furthermore, in both of the alternatives for the case of box 3, it was also feasible to reduce the bag size, which meant there was a $5 \%$ saving in plastic (and its waste).

Overall logistics savings from the changes in these three boxes exceeded 120,000 euros per annum. Likewise, the environmental impact has been reduced because there is an annual reduction in the amount of cardboard (and associated waste) used of 70 tons, and, with the change in bags for box 3 , a reduction of plastic (and associated waste) of 2.5 tons. Logically, by increasing palletizing efficiency, the environmental impact of transport is also reduced. To explain the origin of these improvements in terms of efficiency and sustainability, we can supply the following data: on the one hand, the boxes are comparatively more economical and sustainable (less cardboard used per bag); and on the other hand, 300,000 boxes are no longer handled throughout the supply chain because of those boxes for which the 
number of bags has been increased; finally, the handling, storing and transport of over 1500 pallets has been avoided every year thanks to improved efficiency of palletizing.

\subsection{Case 2. Container System}

In the second case study, the firm was created at the end of the 1980s and belongs to the textile industry. It specializes in designing and manufacturing clothes and accessories which it sells at over 140 points of sale it has in Europe, mainly in Spain and Portugal, turning over around 13 million euros annually. Although the firm does some manufacturing in-house, most of its garments are produced in Asia, particularly in China. In this context, good use of international transport is key when improving cost standards and, clearly, reducing any environmental impact. For that reason, the project for rationalizing transport costs was centered on Asia. Within the framework for this project, a working team was set up that included the head of purchasing, the head of logistics, the head of marketing and the authors of this paper.

Regarding packaging, the firm and its Asian suppliers had standardized the use, for most orders, of a corrugated cardboard slotted box (the most efficient) with external dimensions of $600 \times 400 \times 300 \mathrm{~mm}$ (length $\times$ width $\times$ height). Each garment was individually bagged (primary packaging). Examples of the garments are trousers, shorts, tee-shirts, polo shirts, jackets and swimwear. Each box contained only garments of the same model, color and size. The average number of garments folded into each box was 20 units (in two piles of 10).

The main reason put forward by the firm for having selected the modular base box $(600 \times 400 \mathrm{~mm})$ was that it was efficient when potentially palletized onto a standard EUR or American pallet. At the same time, the height of the box met the need of ensuring the minimum capacity for the folded garments coming from the suppliers. However, when the working team analyzed the logistics flow in depth, it was discovered that at no stage of the supply chain was the product ever palletized.

Thus, during the supply stage, transport was based on grouping in ISO containers. Depending on the geographical area in which the supplier was located, demand and the time of year, 20-foot (20 DC), 40 -foot (40 DC) or 40-foot "high cube" (40 HC) containers were used. Boxes were stowed in the containers in order to make the most of the available volume because, as mentioned previously, standard containers do not allow efficient palletizing. At the same time, pallets were not used in the warehousing and picking processes at the firm's main platform in Spain. Instead, the boxes were placed directly on shelves. Finally, parcel service firms were used in the distribution stage to points of sale (in some cases reusing the same boxes used by the suppliers) and there was some residual use of pallets. What is more, the firm's own strategy did not envisage significant changes regarding pallet use at any point of its supply chain in either the mid or long term.

The working team analyzed how the garments were placed in the boxes and it was noted that there was space between the two columns of folded clothes and the inside of the box, particularly at the bottom. Given this situation, the working team analyzed how each garment was folded, and consulted with the suppliers as to whether it was feasible to adjust the fold so that the garments took up less volume, which facilitated a reduction of $3 \%-5 \%$ in the quantity of plastic used for the bag.

With these changes, and given that the box did not need to be designed for efficient palletizing, the impact of adjusting the internal base of the box to the maximum possible for the new garment fold (580 mm and $390 \mathrm{~mm}$ instead of $600 \times 400 \mathrm{~mm}$ ) was looked into. At the same time, the potential impact of increasing the height of the box so that it could contain more garments was investigated (heights of 310, 320, 330 and 340, respectively). In practice, this meant studying the impact of using feasible alternatives that were more or less efficient in the $\mathrm{m}^{2} / \mathrm{m}^{3}$ ratio. Likewise, a professional app on the web (www.pier2pier.com) was used to simulate container filling. In order to develop this container simulation, the following internal dimensions were considered $(\mathrm{L} \times \mathrm{W} \times \mathrm{H})$ : for $20 \mathrm{DC} 5,898 \times 2,352$ $\times 2,393 \mathrm{~mm}$; for $40 \mathrm{DC} 12,035 \times 2,352 \times 2,393 \mathrm{~mm}$; for $40 \mathrm{HC} 12,035 \times 2,352 \times 2,695 \mathrm{~mm}$ ).

The results of global analysis are given in Tables 3 and 4 . Table 3 shows how, thanks to the two measures taken (folding and redesigning), the most efficient box is the $580 \times 390 \times 340 \mathrm{~mm}$ option, 
increasing 4 garments per box with a better $\mathrm{m}^{2} / \mathrm{m}^{3}$ ratio of $5.3 \%$ and a better $\mathrm{m}^{2} /$ garment ratio of $15.7 \%$. Simultaneously, for this new box, Table 4 shows an increase in the number of boxes per container (between $4 \%$ and $7 \%$ ) and the number of garments per container (between $25 \%$ and $28 \%$ ).

Table 3. Analysis of alternatives (boxes).

\begin{tabular}{cccccc}
\hline $\begin{array}{c}\text { Box Options } \\
\text { (External Dimensions; } \mathbf{L}^{*} \mathbf{W}^{*} \mathbf{H}, \\
\mathbf{m m})\end{array}$ & Volume $\left(\mathbf{m}^{\mathbf{3}}\right)$ & $\begin{array}{c}\text { Box Surface } \\
\left(\mathbf{m}^{2} \mathbf{)}\right.\end{array}$ & $\mathbf{m}^{2} / \mathbf{m}^{\mathbf{3}}$ & $\begin{array}{c}\text { Number of } \\
\text { Garments/Box }\end{array}$ & $\mathbf{m}^{2} /$ Garment \\
\hline Initial Box 1 $\left(600^{*} 400^{*} 300\right)$ & 0.072 & 1.4 & 19.44 & 20 & 0.0700 \\
Option 1 $\left(580^{*} 390^{*} 310\right)$ & 0.0701 & 1.358 & 19.37 & 20 & 0.0679 \\
& $(-2.61 \%)$ & $(-3 \%)$ & $(-0.4 \%)$ & $(+0 \%)$ & $(-3 \%)$ \\
Option 2 $\left(580^{*} 390^{*} 320\right)$ & 0.0723 & 1.3774 & 19.03 & 22 & 0.0626 \\
Option 3 & $(+0.53 \%)$ & $(-1.61 \%)$ & $(-2.14 \%)$ & $(+10 \%)$ & $(-10.56 \%)$ \\
$\left(580^{*} 390^{*} 330\right)$ & 0.0746 & 1.3968 & 18.71 & 22 & 0.0635 \\
Option 4 & $(+3.68 \%)$ & $(-0.23 \%)$ & $(-3.77 \%)$ & $(+10 \%)$ & $(-9.3 \%)$ \\
$\left(580^{*} 390^{*} 340\right)$ & 0.0769 & 1.4162 & 18.41 & 24 & 0.0590 \\
& $(+6.82 \%)$ & $(+1.16 \%)$ & $(-5.3 \%)$ & $(+20 \%)$ & $(-15.7 \%)$ \\
\hline
\end{tabular}

Table 4. Analysis of alternatives (containers).

\begin{tabular}{|c|c|c|c|c|c|c|}
\hline $\begin{array}{c}\text { Box Options } \\
\text { (External Dimensions; } \\
\mathrm{L}^{*} \mathrm{~W}^{*} \mathrm{H}, \mathrm{mm} \text { ) }\end{array}$ & $\begin{array}{c}\text { Number } \\
\text { Boxes in } 20 \\
\text { DC }\end{array}$ & $\begin{array}{l}\text { Number } \\
\text { Garments in } \\
20 \text { DC }\end{array}$ & $\begin{array}{c}\text { Number } \\
\text { Boxes in } 40 \\
\text { DC }\end{array}$ & $\begin{array}{l}\text { Number } \\
\text { Garments in } \\
40 \text { DC }\end{array}$ & $\begin{array}{c}\text { Number of } \\
\text { Boxes in } 40 \\
\text { HC }\end{array}$ & $\begin{array}{c}\text { Number of } \\
\text { Garments in } \\
40 \mathrm{HC}\end{array}$ \\
\hline Initial Box $1\left(600^{*} 400 * 300\right)$ & 392 & 7840 & 830 & 16,600 & 920 & 18,400 \\
\hline Option $1(580 * 390 * 310)$ & $\begin{array}{c}456 \\
(+16.33 \%)\end{array}$ & $\begin{array}{c}9120 \\
(+16.33 \%)\end{array}$ & $\begin{array}{c}912 \\
(+9.88 \%)\end{array}$ & $\begin{array}{c}18,240 \\
(+9.88 \%)\end{array}$ & $\begin{array}{c}1032 \\
(+12.17 \%)\end{array}$ & $\begin{array}{c}20,640 \\
(+12.17 \%)\end{array}$ \\
\hline Option $2(580 * 390 * 320)$ & $\begin{array}{c}432 \\
(+10.2 \%)\end{array}$ & $\begin{array}{c}9504 \\
(+21.22 \%)\end{array}$ & $\begin{array}{c}888 \\
(+6.99 \%)\end{array}$ & $\begin{array}{c}19,536 \\
(+17.69 \%)\end{array}$ & $\begin{array}{c}1010 \\
(+9.78 \%)\end{array}$ & $\begin{array}{c}22,220 \\
(+20.76 \%)\end{array}$ \\
\hline $\begin{array}{c}\text { Option 3 } \\
(580 * 390 * 330)\end{array}$ & $\begin{array}{c}420 \\
(+7.14 \%)\end{array}$ & $\begin{array}{c}9240 \\
(+17.86 \%)\end{array}$ & $\begin{array}{c}864 \\
(+4.1 \%)\end{array}$ & $\begin{array}{c}19,008 \\
(+14.51 \%)\end{array}$ & $\begin{array}{c}986 \\
(+7.17 \%)\end{array}$ & $\begin{array}{c}21,692 \\
(+17.89 \%)\end{array}$ \\
\hline $\begin{array}{c}\text { Option } 4 \\
\left(580^{*} 390 * 340\right)\end{array}$ & $\begin{array}{c}420 \\
(+7.14 \%)\end{array}$ & $\begin{array}{c}10,080 \\
(+28.57 \%)\end{array}$ & $\begin{array}{c}864 \\
(+4.1 \%)\end{array}$ & $\begin{array}{c}20,736 \\
(+24.92 \%)\end{array}$ & $\begin{array}{c}962 \\
(+4.57 \%)\end{array}$ & $\begin{array}{c}23,088 \\
(+25.48 \%)\end{array}$ \\
\hline
\end{tabular}

The improvements undertaken allowed an average reduction of $25 \%$ in logistics costs, which was allocated to each garment. In addition to the saving in transport costs, this final saving included handling (fewer boxes) and the packaging materials themselves (boxes and bags). Logically, the environmental impact was also reduced given that transport use was improved (lower $\mathrm{CO}_{2}$ emissions), fewer raw materials were used in the packaging bags and boxes and any associated waste was reduced.

\subsection{Case 3. Parcel Service System}

In this third case, the firm is specialized in the online sale of delicatessen food products. It was founded in 2012 in Spain and employs some 20 people. Its growing turnover has reached around 1.5 million euros per annum. The firm started by offering a series of "gift" packs designed to contain a predetermined number of bottles of wine and/or spirits. The packs later began to include other gourmet food products with various formats (tins, jars, bags, packets, etc.).

Initially, it was the standard bottle height $(260-270 \mathrm{~mm})$ that conditioned the design of the box for the packs, which was a folder-type box in four different sizes (see Table 5). The folder-type box was chosen for commercial reasons because, along with the aesthetic design and materials used, it reinforced the brand's image, forming an indivisible part of the customer's buying experience. The bottles were placed in the file-type box in one layer $(2 \times 1,3 \times 1,5 \times 1$ boxes $)$ or two layers $(5 \times 2$ box $)$ depending on the number of bottles in the gift pack. 
Table 5. Gift boxes.

\begin{tabular}{ccccc}
\hline Type of Gift Box & $\begin{array}{c}\text { External Length } \\
(\mathbf{m m})\end{array}$ & $\begin{array}{c}\text { External Width } \\
(\mathbf{m m})\end{array}$ & $\begin{array}{c}\text { External Height } \\
(\mathbf{m m})\end{array}$ & $\begin{array}{c}\text { External Volume } \\
\left(\mathbf{m}^{\mathbf{3}}\right)\end{array}$ \\
\hline 1.- Gift box 2*1 & 325 & 185 & 90 & 0.0054 \\
2.- Gift box 3*1 & 325 & 280 & 90 & 0.0082 \\
3.- Gift box 5*1 & 475 & 345 & 100 & 0.0164 \\
4.- Gift box 5*2 & 475 & 345 & 200 & 0.0328 \\
\hline
\end{tabular}

At the same time, the file-type boxes were placed in a master box of the slotted type (the most efficient) to protect them. In order to adapt to the gift pack orders customers could order one or several packs in one order-the firm had 7 different formats of a master box (see Table 6). The biggest box was the most expensive and also, initially, the least used. Clearly, a master box of a specific type had some play in all dimensions around the file-type placed in it so that it could fit inside. Likewise, the firm used bubble wrap as a cushion between the two boxes. In a similar way, the firm used recycled paper shavings inside the gift pack as a protective "bed" and cushioning between the different products being held.

Table 6. Master boxes.

\begin{tabular}{|c|c|c|c|c|c|c|}
\hline Type of Master Box & $\begin{array}{l}\text { External Length } \\
(\mathrm{mm})\end{array}$ & $\begin{array}{c}\text { External } \\
\text { Width }(\mathrm{mm})\end{array}$ & $\begin{array}{l}\text { External Height } \\
(\mathrm{mm})\end{array}$ & $\begin{array}{c}\text { External } \\
\text { Volume } \\
\left(\mathrm{m}^{3}\right)\end{array}$ & $\begin{array}{l}\text { Box Surface } \\
\left(\mathrm{m}^{2}\right)\end{array}$ & $\mathrm{m}^{2} / \mathrm{m}^{3}$ \\
\hline 1.- Master Box $2 \times 1$ & 350 & 200 & 100 & 0.0070 & 0.030 & 47.14 \\
\hline 2.- Master Box $3 \times 1$ & 350 & 300 & 100 & 0.0105 & 0.520 & 49.52 \\
\hline 3.- Master Box $2 \times 2$ & 350 & 200 & 190 & 0.0133 & 0.429 & 32.26 \\
\hline 4.- Master Box $3 \times 2$ & 350 & 300 & 190 & 0.0200 & 0.637 & 31.93 \\
\hline 5.- Master Box $5 \times 1$ & 500 & 360 & 120 & 0.0216 & 0.826 & 38.22 \\
\hline 6.- Master Box $5 \times 2$ & 500 & 360 & 215 & 0.0387 & 0.989 & 25.56 \\
\hline 7.- Master Box $5 \times 3$ & 500 & 360 & 340 & 0.0612 & 1.204 & 19.63 \\
\hline
\end{tabular}

Storage and picking of orders were done at the firm's small warehouse in northwest Spain and transport for distribution was subcontracted out to a parcel service firm. Transport tariffs were based on bands for the box weights depending on the distance and the number of boxes, and there was adjustment for the concept of volumetric weight described earlier.

In this context, and in the light of good sales results, the firm decided to continue enlarging its catalogue of products. Furthermore, they opened up orders to the requirements and demands of customers, without the need to stick exclusively to the restriction of the gift pack format (although these were still available for customers). These new orders were called "open orders". At the same time, the firm's plans for the future envisaged growth in new markets (including international ones), which meant that rationalization of the number of boxes took on greater importance.

The firm launched a project to review its packaging system, with the basic premise of improving the efficiency and sustainability of its logistics activities in its new strategic framework ("open orders" with or without the "gift pack" folder-type box), without altering the concept and dimensions of the folder-type boxes. Likewise, given that there was little history of complaints due to spoilt products, it was decided not to put the protective aspects of the deliveries at risk because of the important impact it could have on the brand's image. The working team was made up of the head of marketing, the head of operations and the authors of this paper. Initially, the working team carried out an analysis of the volumes associated with the different master boxes. This analysis noted that there were volume ranges for boxes that were not covered in the new setting and that this reduced flexibility; thus, they identified a jump in box size almost to double the volume of the previous box (see Figure 4). This meant that, in some "open" orders, there might not be a box of a suitable volume available, which obliged the firm to use more boxes or use a box with a larger-than-necessary volume and more cushioning material. Both cases had negative connotations in terms of logistics efficiency and sustainability. At the same 
time, it was not a good idea to increase the types of boxes available because the loss of economies of scale would negatively affect the box purchase price.

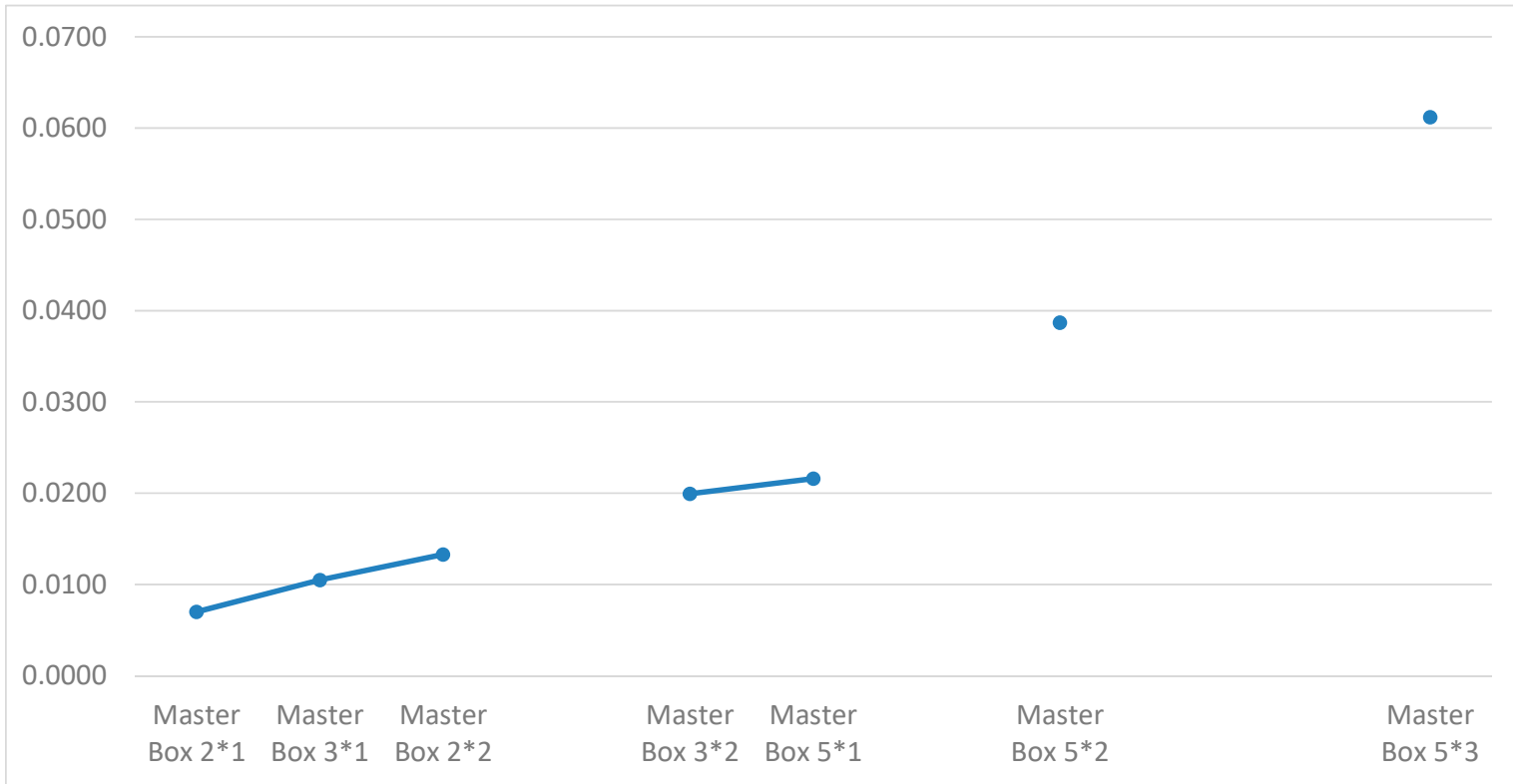

Figure 4. Initial volumes $\left(\mathrm{m}^{3}\right)$ available for orders with the seven master boxes.

The proposed solution was to maintain the number of master boxes and use die cutting to make the height variable in 3 boxes $(3 \times 2 ; 5 \times 2 ; 5 \times 3)$ (see Table 7). This meant that the volume of these boxes could be deployed in two ways-the original box and a cut-down one created by cutting the box in the die-cut area-adapting it in a better way to the orders (see Figure 5). This was all achieved without increasing the number of master box formats and, therefore, without losing economies of scale when buying. Comparatively, consumption of boxes in distribution was reduced (lower buying costs and lower transport costs associated with the number of items).

Table 7. Changes in boxes using die cutting.

\begin{tabular}{ccccc}
\hline $\begin{array}{c}\text { Master Boxes Using Die } \\
\text { Cutting }\end{array}$ & External Length $(\mathbf{m m})$ & External Width (mm) & External Height (mm) & External Volume (m $\left.{ }^{3}\right)$ \\
\hline (Master Box 3*2. Cut 1) & 350 & 300 & 160 & 0.0168 \\
4.- Master Box 3*2 & 350 & 300 & 190 & 0.0200 \\
(Master Box 5*2. Cut 1) & 500 & 360 & 180 & 0.0324 \\
6.- Master Box 5.2 & 500 & 360 & 215 & 0.0387 \\
(Master Box 5*3. Cut 1) & 500 & 360 & 250 & 0.0450 \\
(Master Box 5*3. Cut 2) & 500 & 360 & 300 & 0.0540 \\
7.- Master Box 5*3 & 500 & 360 & 340 & 0.0612 \\
\hline
\end{tabular}




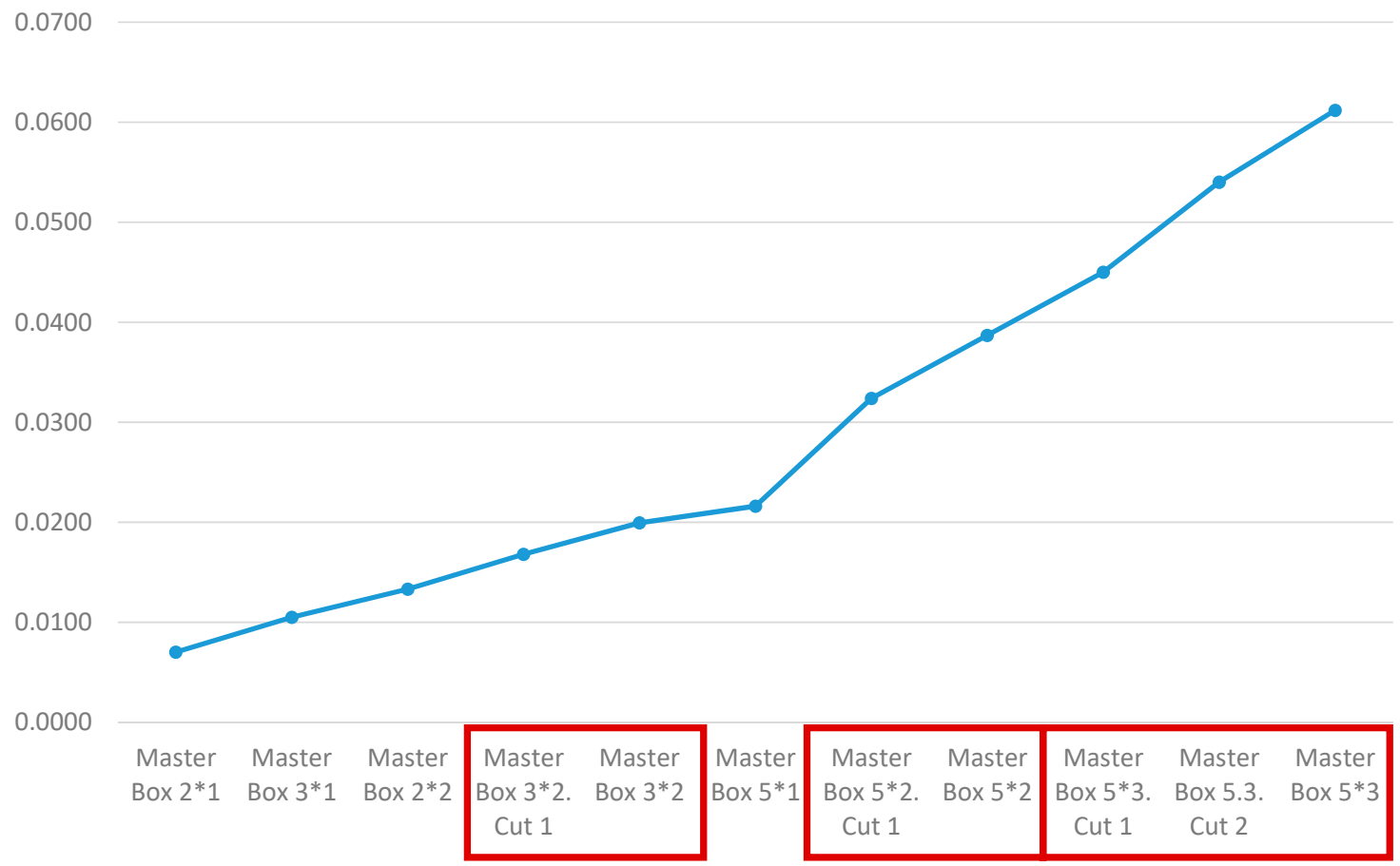

Figure 5. Improved volumes $\left(\mathrm{m}^{3}\right)$ available for orders with the seven master boxes.

Furthermore, these boxes were a better fit in terms of volume, which meant that they contributed to a reduction in transport costs (less likelihood of jumping up to the next tariff band for volumetric weight), and also to a reduction in the use of cushioning material (and its associated waste). Simultaneously, the master boxes $3 \times 1$ and $5 \times 1$, with the worst $\mathrm{m}^{2} / \mathrm{m}^{3}$ ratio, are devoted specifically to orders with gift boxes $3 \times 1$ and $5 \times 1$ (see Table 6). Overall cost savings linked to this new approach to the packaging system are estimated at $10 \%$.

Logically, the case put forward here is conditioned or qualified by the size and turnover of the firm. Thus, as the undisputed worldwide leader of e-commerce, the US firm Amazon (www.amazon.com), the way to improve the logistics system by means of box design presents similar strategies though, of course, they would be adapted to its turnover. Order picking is done at Amazon's logistics centeres, where aspects of automation and selection of the best packing for grouping or protection (based on cardboard boxes and recyclable envelopes) are especially important. To minimize packaging size and the number packages linked to each order, the firm has a range of over 80 packaging formats available.

In this context, Amazon has promoted improvement in efficiency and sustainability in its logistics activities by promoting, among its product suppliers, simplification of primary package components, reduction of the packaging's volume and, principally, making the primary packaging usable for delivery direct to the customer. Since the "Free Frustration Packaging" (FFP) strategy was launched in 2007 , savings have been made in consumption equal to over 244,000 tons of packaging materials and over 500 million boxes. The firm estimates that with these measures, approximately half of deliveries can be made in packages that are smaller than the current one with a volume reduction estimated at between $34 \%$ and $80 \%$. In a parallel way, Amazon is also attempting to increase order groupings to the same customer so as to reduce the number of packages being delivered to them. Likewise, since 2016, the firm has been using a system called "Box on Demand" which facilitates dynamic selection and improved packaging for each order by applying machine learning.

\section{Discussion and Conclusions}

We live in exciting, uncertain times. Economically, the level of competition in every market is forcing firms to focus their efforts on substantially improving their standards of quality, service and, 
of course, cost, as a way of guaranteeing their long-term survival. Logically, in markets that are increasingly more global and volatile, the efforts of each individual firm to improve its competitiveness and sustainability, although necessary, are not enough because the effort should be addressed in a coordinated way throughout the whole supply chain.

Thus, packaging, especially the box, plays an overarching and facilitating role to actively contribute to sustainable improvement of supply chains within a conceptual framework called "Sustainable Packaging Logistics". In this context, this paper has proposed a systematic and dynamic method that connects decisions about box dimensions with measurement of overall efficiency and sustainability of supply chains. Likewise, this method was applied successfully in three firms with different logistics systems (pallet, container and parcel).

This novel approach is considered to be particularly useful in the research sphere in order to open new lines of study and in the professional sphere, where it actively contributes to the improvements in competitiveness and sustainability. At the same time, the "Action Research" methodology adopted by the authors to implement the model in the three case studies can also be considered as novel. Indeed, exchanges between the academic and business worlds in the realm of packaging design are mutually beneficial. Researchers obtain a "test bench" on which to qualify, enrich and validate their conceptual proposals. Firms obtain knowledge transfer that allows them to improve their competitiveness in terms of efficiency and sustainability, not just during the project's development but also in the future with new products and logistics needs. The firms thus become "learning organizations".

Logically, the paper also presents limitations linked, for example, to the low number of implementations of the model (three companies). At the same time, the proposed model is centered on the field of decisions regarding box dimensions in order to compare overall chain costs for different design alternatives. However, by focusing on only the secondary packaging level and only one of the five design decisions (dimensions), some relevant aspects may not have been fully considered as the members of the work team would have assessed them subjectively. Likewise, the measurement of the environmental impact-in direct terms with the Green dot and in indirect terms with resource consumption costs such as packaging materials and transport costs-might have overlooked other environmental impacts that would have been picked up on if other specific more complex technical areas such as LCA had been considered. That is why we propose that future research should deal with the implementation of this method in different companies and supply chains, directly integrating more design decisions and other measurement systems so that it can be validated more widely.

There are still quasi-unexplored areas in the area of packaging design which particularly affect secondary packaging or the box. For example, the possibility of looking into the integration of packaging design into the design of the product itself. An example of this is the integrated design of products and packaging at IKEA which is providing such good results in logistics efficiency and sustainability [40].

At the same time, e-commerce is here to stay and plays a significant role in the way in which all types of products are commercialized in a framework of global competition. However, the sudden emergence and consolidation of e-commerce will not mean the elimination or disappearance of the other channels for commercialization (the omni-channel strategy), although, logically, it will force their redefinition and redesign [71]. However, if at a packaging level, the deployment of e-commerce already involves sufficient challenges that need overcoming, then this difficulty only grows when channels become more complex in order to support an omni-channel context, and grows even more if an attempt is made to integrate or to find shared solutions in diverse logistics systems (for example, palletizing, containers and parcel services).

At the same time, work is going on in the technology field for distribution with the development of "smart boxes" promoted conceptually by the "Physical Internet" approach [72], standard boxes that can be reused and respect the environment. These "smart boxes" will be filled, handled, warehoused and transported (in many cases automatically) in such a way that they integrate efficiently into the load units 
by means of shared installations and open networks [73]. Therefore, the concept of box standardization and modularity is a key element in this new approach and should, reasonably, go hand-in-hand with the $600 \times 400 \mathrm{~mm}$ module and standard EUR and American pallets [53]. But what about the container?

Author Contributions: J.G.-A. designed the conceptual and applied basis for the paper, developing the literature review and the coordination of the different sections of the paper. J.A.C.-B. was responsible for mathematical analysis. A.T.G.-P.G. and J.C.P.-P. worked on the development of case studies. All authors read and approved the final manuscript for submission.

Funding: This research received no external funding.

Conflicts of Interest: The authors declare no conflict of interest.

\section{References}

1. McKinnon, A.C.; Ge, Y. Use of a synchronised vehicle audit to determine opportunities for improving transport efficiency in a supply chain. Int. J. Logist. Res. Appl. 2004, 7, 219-238. [CrossRef]

2. European Commission. White Paper-Roadmap to a Single European Transport Area: Towards a Competitive and Resource Efficient Transport System; Report; European Commission: Brussels, Belgium, 2011.

3. Santén, V. Toward more efficient logistics: Increasing load factor in a shipper's road transport. Int. J. Logist. Manag. 2017, 28, 228-250. [CrossRef]

4. García-Arca, J.; Prado-Prado, J.C.; Fernández-González, A.J. Integrating KPIs for improving efficiency in road transport. Int. J. Phys. Distrib. Logist. Manag. 2018, 48, 931-951. [CrossRef]

5. Saghir, M. Packaging Logistics Evaluation in the Swedish Retail Supply Chain; Lund University: Lund, Sweden, 2002.

6. Klevas, J. Organization of packaging resources at a product-developing company. Int. J. Phys. Distrib. Logist. Manag. 2005, 35, 116-131. [CrossRef]

7. Hellström, D.; Saghir, M. Packaging and logistics interactions in retail supply chain. Packag. Technol. Sci. 2006, 20, 197-216. [CrossRef]

8. Verghese, K.; Lewis, H. Environmental innovation in industrial packaging: a supply chain approach. Int. J. Prod. Res. 2007, 45, 4381-4401. [CrossRef]

9. García-Arca, J.; Prado-Prado, J.C. Packaging design model from a supply chain approach. Supply Chain Manag. Int. J. 2008, 13, 375-380. [CrossRef]

10. Azzi, A.; Battini, D.; Persona, A.; Sgarbossa, F. Packaging design: General framework and research agenda. Packag. Technol. Sci. 2012, 25, 435-456. [CrossRef]

11. García-Arca, J.; Prado-Prado, J.C.; González-Portela Garrido, A.T. "Packaging logistics": Promoting sustainable efficiency in supply chains. Int. J. Phys. Distrib. Logist. Manag. 2014, 44, 325-346. [CrossRef]

12. García-Arca, J.; Prado-Prado, J.C.; González-Portela Garrido, A.T. Drivers and Stages in "Packaging Logistics": An Analysis in the Food Sector. In Enhancing Synergies in a Collaborative Environment; Springer: Cham, Switzerland, 2015; pp. 51-59.

13. Dominic, C.A.S.; Östlund, S.; Buffington, J.; Masoud, M.M. Towards a Conceptual Sustainable Packaging Development Model: a Corrugated Box Case Study. Packag. Technol. Sci. 2015, 28, 397-413. [CrossRef]

14. Pålsson, H.; Hellström, D. Packaging logistics in supply chain practice-Current state, trade-offs and improvement potential. Int. J. Phys. Distrib. Logist. Res. Appl. 2016, 19, 1-18. [CrossRef]

15. García-Arca, J.; Prado-Prado, J.C.; González-Portela Garrido, A.T. Sustainable Packaging Logistics. The link between Sustainability and Competitiveness. Sustainability 2017, 9, 1098. [CrossRef]

16. Rundh, B. The role of packaging within marketing and value creation. Br. Food J. 2016, 118, $2491-2511$. [CrossRef]

17. Krishnaa, A.; Cianb, L.; Aydıno־glu, N.Z. Sensory Aspects of Package Design. J. Retail. 2017, 93, 43-54. [CrossRef]

18. Sohrabpour, V.; Oghazi, P.; Olsson, A. An Improved Supplier Driven Packaging Design and Development Method for Supply Chain Efficiency. Packag. Technol. Sci. 2016, 29, 161-173. [CrossRef]

19. Dickner, A. Sustainable Packaging. An IKEA Prevension; Waste Prevention in Practice; Pro Europe Seminar: Brussels, Belgium, 2012. 
20. Grönman, K.; Soukka, R.; Järvi-Kääriäinen, T.; Katajajuuri, J.-M.; Kuisma, M.; Koivupuro, H.-K.; Ollila, M.; Pitkänen, M.; Miettinen, O.; Silvenius, F.; et al. Framework for Sustainable Food Packaging Design. Packag. Technol. Sci. 2013, 26, 187-200. [CrossRef]

21. Molina-Besch, K. Prioritization guidelines for green food packaging development. Br. Food J. 2016, 118, $2512-2533$. [CrossRef]

22. Svanes, E.; Vold, M.; Møller, H.; Pettersen, M.K.; Larsen, H.; Hanssen, O.J. Sustainable packaging design: a holistic methodology for packaging design. Packag. Technol. Sci. 2010, 23, 161-175. [CrossRef]

23. Albrecht, S.; Brandstetter, P.; Beck, T.; Fullana-Palmer, P.; Grönman, K.; Baitz, M.; Fischer, M. An extended life cycle analysis of packaging systems for fruit and vegetable transport in Europe. Int. J. Life Cycle Assess 2013, 18, 1549-1567. [CrossRef]

24. Mollenkopf, D.; Closs, D.; Twede, D.; Lee, S.; Burgess, G. Assessing the viability of reusable packaging: a relative cost approach. J. Bus. Logist. 2005, 26, 169-197. [CrossRef]

25. Williams, H.; Wikström, F.; Löfgren, M. a life cycle perspective on environmental effects of customer focused packaging development. J. Clean. Prod. 2008, 16, 853-859. [CrossRef]

26. Verghese, K.; Lewis, H.; Lockrey, S.; Williams, H. Packaging's Role in Minimizing Food Loss and Waste across the Supply Chain. Packag. Technol. Sci. 2015, 28, 603-620. [CrossRef]

27. Koeijer, B.; Lange, J.; Wever, R. Desired, Perceived, and Achieved Sustainability: Trade-Offs in Strategic and Operational Packaging Development. Sustainability 2017, 9, 1923. [CrossRef]

28. Vernuccio, M.; Cozzolino, A.; Michelin, I.L. An exploratory study of marketing, logistics, and ethics in packaging innovation. Eur. J. Innov. Manag. 2010, 13, 333-354. [CrossRef]

29. Nordin, N.; Selke, S. Social aspect of sustainable packaging. Packag. Technol. Sci. 2010, 23, 317-326.

30. Molina-Besch, K.; Pålsson, H. Packaging for Eco-Efficient Supply Chains: Why Logistics Should Get Involved in the Packaging Development Process. In Sustainable Logistics (Transport and Sustainability); Macharis, C., Melo, S., Woxenius, J., Van Lier, T., Eds.; Emerald Group Publishing Limited: Bingley, UK, 2014; Volume 6, pp. 137-163.

31. Lee, S.G.; Lye, S.W. Design for manual packaging. Int. J. Phys. Distrib. Logist. Manag. 2003, 33, $163-189$. [CrossRef]

32. Chan, F.T.S.; Chan, H.K.; Choy, K.L. a systematic approach to manufacturing packaging logistics. Int. J. Adv. Manuf. Technol. 2006, 29, 1088-1101. [CrossRef]

33. Olander-Roese, M.; Nilsson, F. Competitive advantages through packaging design-prepositions for supply chain effectiveness and efficiency. In Proceedings of the 17th International Conference on Engineering Design (ICED), Stanford, CA, USA, 24-27 August 2009; pp. 279-290.

34. Sohrabpour, V.; Hellström, D.; Jahre, M. Packaging in developing countries: Identifying supply chain needs. J. Humanit. Logist. Supply Chain Manag. 2012, 2, 183-205. [CrossRef]

35. ISO 14040: 2006. Environmental Management_Life Cycle Assessment_Principles and Framework; ISO: Geneva, Switzerland, 2006.

36. Molina-Besch, K.; Pålsson, H. a simplified environmental evaluation tool for food packaging to support decision-making in packaging development. Packag Technol Sci. 2020, 1-17. [CrossRef]

37. Hellström, D.; Nilsson, F. Logistics-driven packaging innovation: a case study at IKEA. Int. J. Retail Distrib. Manag. 2011, 39, 638-657. [CrossRef]

38. Kye, D.; Lee, J.; Lee, K. The perceived impact of packaging logistics on the efficiency of freight transportation (EOT). Int. J. Phys. Distrib. Logist. Manag. 2013, 43, 707-720. [CrossRef]

39. Accorsi, R.; Cascini, A.; Cholette, S.; Manzini, R.; Mora, C. Economic and environmental assessment of reusable plastic containers: a food catering case study. Int. J. Prod. Econ. 2014, 152, 88-101. [CrossRef]

40. García-Arca, J.; González-Portela Garrido, A.T.; Prado-Prado, J.C. Packaging as support of efficiency and sustainability in supply chain. An applied approach. Dir. Organ. (DyO) 2013, 51, 33-43.

41. Gelici-Zeko, M.M.; Lutters, D.; Klooster, T.R.; Weijzen, P.L.G. Studying the influence of packaging design on consumer perceptions (of dairy products) using categorizing and perceptual mapping. Packag. Technol. Sci. 2012, 26, 215-228. [CrossRef]

42. Wever, R.; Vogtländer, J. Eco-efficient Value Creation: An Alternative Perspective on Packaging and Sustainability. Packag. Technol. Sci. 2013, 26, 229-248. [CrossRef]

43. Bertoluci, G.; Leroy, Y.; Olsson, A. Exploring the environmental impacts of olive packaging solutions for the European food market. J. Clean. Prod. 2014, 64, 234-243. [CrossRef] 
44. García-Arca, J.; González-Portela Garrido, A.T.; Prado-Prado, J.C. Implementing “sustainable packaging logistics". An analysis in liquid detergents. Dir. Organ. (DyO) 2016, 60, 47-56.

45. Hellström, D.; Olsson, A. Managing Packaging Design for Sustainable Development; Wiley: London, UK, 2017.

46. García-Arca, J.; González-Portela Garrido, A.T.; Prado-Prado, J.C. Organizational best practices in packaging design. An analysis in perfumery and cleaning products. Dir. Organ. (DyO) 2019, 68, 5-19.

47. Morabito, R.; Morales, S.R.; Widmer, J.A. Loading optimization of palletized products on trucks. Transp. Res. Part E Logist. Transp. Rev. 2000, 36, 285-296. [CrossRef]

48. Wever, R. Design for volume optimization of packaging for durable goods. Packag. Technol. Sci. 2011, 24, 211-222. [CrossRef]

49. Gamez Albán, H.M.; Soto Cardona, O.C.; Mejía Argueta, C.; Tullio Sarmiento, A. a cost-efficient method to optimize package size in emerging markets. Eur. J. Oper. Res. 2015, 241, 917-926. [CrossRef]

50. Mejía-Argueta, C.; Soto-Cardona, O.C.; Albán, G.; Mauricio, H.; Moreno-Moreno, J.P. Minimum cost package size analysis in the supply chain: a case study in Colombia. Estud. Gerenc. 2015, 31, 111-121.

51. García-Arca, J.; González-Portela Garrido, A.T.; Comesaña-Benavides, J.A.; Prado-Prado, J.C. How to Design an Efficient and Sustainable Box? In Engineering Systems and Networks; Lecture Notes in Management and Industrial Engineering; Amorim, M., Ferreira, C., Vieira Junior, M., Prado, C., Eds.; Springer: Cham, Switzerland, 2017.

52. Faccio, M.; Gamberi, M.; Pilati, P.; Bortolini, F. Packaging strategy definition for sales kits within an assembly system. Int. J. Prod. Res. 2015, 53, 3288-3305. [CrossRef]

53. Landschützer, C.; Ehrentraut, F.; Jodin, D. Containers for the Physical Internet: Requirements and engineering design related to FMCG logistics. Logist. Res. 2015, 8, 1-22. [CrossRef]

54. Coughlan, P.; Coghlan, D. Action research for operations management. Int. J. Oper. Prod. Manag. 2002, $22,220-240$. [CrossRef]

55. Coughlan, P.; Draaijer, D.; Godsell, J.; Boer, H. Operations and supply chain management: The role of academics and practitioners in the development of research and practice. Int. J. Oper. Prod. Manag. 2016, 36, 1673-1695. [CrossRef]

56. Frankel, R.; Naslund, D.; Bolumole, Y. The 'White Space' of logistics research: a look at the role of methods usage. J. Bus. Logist. 2005, 26, 185-209. [CrossRef]

57. Raelin, J.A.; Coghlan, D. Developing managers as learners and researchers: Using action learning and action research. J. Manag. Educ. 2006, 30, 670-689. [CrossRef]

58. Näslund, D.; Kale, R.; Paulraj, A. Action Research in supply chain management-A framework for relevant and rigorous research. J. Bus. Logist. 2010, 31, 331-355. [CrossRef]

59. García-Arca, J.; Prado-Prado, J.C.; González-Portela, A.T. On-shelf availability and logistics rationalization. a participative methodology for supply chain improvement. J. Retail. Consum. Serv. 2020, 52, 101889. [CrossRef]

60. Farooq, S.; O'Brien, C. An action research methodology for manufacturing technology selection: a supply chain perspective. Prod. Plan. Control 2015, 26, 467-488. [CrossRef]

61. ISO 3394: 2012. Packaging. Complete, Filled Transport Packages and Unit Loads. Dimensions of Rigid Rectangular Packages; ISO: Geneva, Switzerland, 2012.

62. ISO 6780: 2003. Flat Pallets for Intercontinental Materials Handling. Principal Dimensions and Tolerances; ISO: Geneva, Switzerland, 2003.

63. ECR Europe. The Efficient Unit Loads Report; ECR Europe: Bruselas, Belgium, 1997.

64. AECOC. RAL. Unidades de Carga Eficientes; AECOC: Barcelona, Spain, 2012.

65. ISO 830: 1999. Freight Containers. Vocabulary; ISO: Geneva, Switzerland, 1999.

66. Wang, F.; Hu, Y. Research on green express packaging design under the electronic commerce. Open J. Bus. Manag. 2016, 4, 621-628. [CrossRef]

67. Pålsson, H.; Pettersson, F.; Winslott Hiselius, L. Energy consumption in e-commerce versus conventional trade channels-Insights into packaging, the last mile, unsold products and product returns. J. Clean. Prod. 2017, 16, 765-778. [CrossRef]

68. Pålsson, H. Packaging Logistics. Understanding and Managing the Economic and Environmental Impacts of Packaging in Supply Chains; Kogan Page: London, UK, 2018.

69. Regattieri, A.; Santarelli, G.; Gamberi, M.; Mora, C. a new paradigm for packaging design in web-based commerce. Int. J. Eng. Bus. Manag. 2014, 6, 1-11. 
70. Regattieri, A.; Santarelli, G.; Piana, F. Packaging Logistics. In Operations, Logistics and Supply Chain Management; Lecture Notes in Logistics; Zijm, H., Klumpp, M., Regattieri, A., Heragu, S., Eds.; Springer: Cham, Switzerland, 2019.

71. Freichel, S.; Wollenburg, J.; Wörtge, J.K. The role of packaging in omni-channel fashion retail supply chains -How can packaging contribute to logistics efficiency? Logist. Res. 2020, 13, 1-20.

72. Montreuil, B.; Meller, R.D.; Ballot, E. Towards a Physical Internet: The Impact on Logistics Facilities and Material Handling Systems Design and Innovation; Material Handling Industry of America: Charlotte, NC, USA, 2010; pp. 305-327.

73. Zhang, Y.; Liu, S.; Liu, Y.; Li, R. Smart box-enabled product-service system for cloud logistics. Int. J. Prod. Res. 2016, 54, 6693-6706. [CrossRef]

(C) 2020 by the authors. Licensee MDPI, Basel, Switzerland. This article is an open access article distributed under the terms and conditions of the Creative Commons Attribution (CC BY) license (http://creativecommons.org/licenses/by/4.0/). 